\title{
Using integrated electronic environments for collaborative teaching/learning ${ }^{\text {in }}$
}

\author{
Paul A. Kirschner * \\ Open University of the Netherlands/University of Maastricht, PO Box 2960, 6401 Heerlen, \\ The Netherlands
}

\begin{abstract}
Comparative international reports and evaluation reports or audits on the quality of university studies reflect a concern about the quality of graduates in their plea for more skillsoriented education, more real-life orientation of study, more group work and interdisciplinary collaboration, less emphasis on declarative knowledge, et cetera. This transformation of education requires a new approach to the design, development, and implementation of both curricula and education; a reengineering of the instructional design process. The position of this contribution is that traditional didactic instruction and instructional design models - at least at the level of higher post-secondary education - must be relegated to the past. The future (and even the today) of learning is constructivist design and development of collaborative and cooperative learning situations in powerful integrated electronic environments.
\end{abstract}

Keywords: Collaborative learning; Electronic learning environments; Constructivist instructional design

\section{Context}

There is a growing concern in professional contexts about performance levels of new recruits and existing staff (Boyatzis, 1982; De Snoeck, 1997). Graduates of universities have the knowledge necessary to do the job, but miss the "higher order skills" and attitudes necessary to do the job properly.

In educational contexts there is a growing call for competency-based education; although the concept of competencies is not always used. Competencies can be con-

\footnotetext{
This paper is based on the author's keynote address presented at the 8th EARLI Conference, Göteborg, Sweden, August 1999.

* Tel.: +45-576-2361; fax: +45-576-2802.

E-mail address: paul.kirschner@ou.nl (P.A. Kirschner).
} 
strued as abilities that enable learners to recognise and define new problems in their domain of study and - future - work as well as solve these problems (Kirschner, van Vilsteren, Hummel, \& Wigman, 1997). According to Keen (1992), competencies refer to the ability to operate in ill-defined and ever-changing environments, to deal with non-routine and abstract work processes, to handle decisions and responsibilities, to work in groups, to understand dynamic systems, and to operate within expanding geographical and time horizons. In other words, competencies are a combination of complex cognitive and higher-order skills, highly integrated knowledge structures, interpersonal and social skills, and attitudes and values. Acquired competencies enable learners to apply these skills and attitudes in a variety of situations (transfer) and over an unlimited time span (lifelong learning) (van Merriënboer, 1999).

In educational circles, educational designers are moving from cognitive, often rule based instructional design for efficient and effective teaching towards constructivist instructional design for competency based learning. The problem is that this is not a question of adaptation of the design methodology used, but is a question of beginning anew.

Curricula based upon a competency-based paradigm require an educational institution to begin from scratch. These curricula are based upon a network of interrelated, often heterarchically organized competencies relating to what a professional can and must do. These competencies subsume, in turn, nested networks of knowledge, skills and attitudes that cannot and may not be pigeon holed into quasi-complete, independent courses. It is no longer a question of just-in-case learning, but rather of justin-time learning. This is further complicated by the social and attitudinal aspects of the profession. These knowledge, skills and attitudes also cannot be pigeon holed into courses. They require learning settings in which the knowledge can be gained and the skills can be acquired in authentic, meaningful contexts, where the necessary interactions with others are fundamental elements of the setting and where the student can reflect upon what he or she has done and develop attitudes intrinsic to the profession. Finally, the assessment of this type of learning requires (specially) adapted assessment situations and procedures specific to assessing the attainment of the intended competencies.

This earthquake in thinking about education means that we must approach the design, development, and implementation of such education in a way that the achievement and assessment of those competencies is made possible and is facilitated. This means a reengineering of the instructional design process.

\section{Constructivism/constructivist philosophy}

Educational and instructional design has gone through a number of phases in the second half of this century. The first significant steps in modeling instructional design were based upon behaviourist psychology. This was followed in the sixties and seventies by cognitive psychology culminating with the third and fourth editions of The conditions of learning (Gagné, 1985) holding that by analysing the goals of education 
one can devise how the achievement of those goals can be met. These theories assume that one can describe a subject matter domain in terms of learning goals, and can then develop instruction for each of the learning goals - taking the optimal conditions of learning for each goal into account. This may work well for domains characterised by independent learning goals, but certainly not for developing competencies that are characterised by highly integrated, complex sets of learning goals.

The current "rage" is constructivism, which, however, is neither an approach to nor a model for instructional design. It is a philosophy of learning based on the idea that knowledge is constructed by learners — and eventually "the one(s) who know(s)" - based on their mental and social activity. Learners are active in seeking meaning. Consistent with this view, learning (not teaching!) must be situated in a rich context, reflective of real world contexts, for this constructive process to occur and for transfer to environments beyond the school to be possible.

Constructivism holds that in order to learn, learning needs to be situated in problem solving in real-life contexts (Brown, Collins, \& Duguid, 1989) where the environment is rich in information and where there are no right answers (embedded knowledge). The tasks must be authentic and are best learnt through cognitive apprenticeship (Collins, 1988) on the part of the learner in a rich environment. Meaning is negotiated through interactions with others where multiple perspectives on reality exist (von Glasersfeld, 1988). Reflexivity is essential and must be nurtured. Finally, all of this is best (and possibly only) achieved when learning takes place in ill-structured domains (Spiro, Coulson, Feltovich, \& Anderson, 1988).

\section{Learning through collaboration and co-operation}

Diana Laurillard, in her groundbreaking book Rethinking university teaching (Laurillard, 1993), defines (university) teaching as that activity of persons (usually experts) which makes academic student learning possible. Academic student learning is defined as achieving the ability to articulate other peoples' descriptions of the world. She considers teaching to be a rhetorical activity, which seeks "to persuade students to change the way they experience the world. It has to create the environment that will enable students to learn the descriptions of the world devised by others" (p. 28). It is, in essence, "mediated learning allowing students to acquire knowledge of someone else's way of experiencing the world" (p. 29). This view of teaching is analogous to what Peter Goodyear (1998) calls the traditional academic view of learning which places value on the disinterested acquisition of academic knowledge.

More in line with current thinking on the need for the acquisition of competencies in higher post secondary education are the vocationalist and the reflexive views of learning posited by Goodyear (1998).

The vocationalist view of learning, one of operational competence, holds that employers want higher education to more closely attend to what they mean that they need in graduates they recruit. These demands refer to generic skills or competencies (e.g. Harvey \& Mason, 1996; Assiter, 1995). Harvey and Knight (1996) conclude 
that organisations that recruit graduates are looking, above all else, for transformative potential. That is, they want new graduates entering their employ to have the capacity to transform their organisation, not merely to enhance its productivity and competitiveness along current lines.

Critical being and reflexivity, a third conception, is best articulated in the writing of Ronald Barnett (1997a, 1997b) Barnett (1997b). He argues that individual reflexivity ("the capacity to go on interrogating one's taken-for-granted universe") is necessary for dealing with an essentially unknowable modern world.

These two last types of learning cannot be achieved in traditional contiguous didactic (academic) teaching and learning settings, which are more often than not both individual and competitive in nature. They require the implementation of another approach to learning in a setting, where there are shared realistic and relevant problems, where there are shared needs and goals, where there is room for multiple perspectives on the problems and their solutions, where there are shared responsibilities both for the process of achieving a final product and for the product itself, and where there is mutual trust in one another such that participants are valued for their contributions and their initiative. In other words, in a collaborative and/or cooperative learning setting.

\subsection{Collaboration and co-operation}

Collaborative learning supports the use of effective discursive learning methods (make explicit, discuss, reason, and reflect, convince) while allowing for the acquisition of essential social and communication skills (Dillenbourg, Baker, Blaye, \& O’Malley, 1995; Mirande, Riemersma, \& Veen, 1997). One of the best discussions of what collaborative and co-operative learning are can be found in Panitz (1996). According to him, collaboration is a philosophy of interaction and personal lifestyle while co-operation is a structure of interaction designed to facilitate the accomplishment of an end product or goal through people working together in groups.

Collaborative learning [italics added] is a personal philosophy, not just a classroom technique. ... There is a sharing of authority and acceptance of responsibility among group members for the groups actions. The underlying premise of collaborative learning is based upon consensus building through co-operation by group members, in contrast to competition in which individuals best other group members.

Co-operative learning [italics added] is defined by a set of processes which help people interact together in order to accomplish a specific goal or develop an end product which is usually content specific. It is more directive than a collaborative system of governance and closely controlled by the teacher. While there are many mechanisms for group analysis and introspection the fundamental approach is teacher-centred whereas collaborative learning is more student centred.

Although there are differences, collaborative and co-operative learning share a large number of assumptions and areas of agreement. The commonalties are:

- learning takes place in an active mode;

- the teacher is more a facilitator than a "sage on the stage"; 
- teaching and learning are shared experiences between teacher and students;

- students participate in small-group activities;

- students must take responsibility for learning;

- discussing and articulating one's ideas in a small-group setting enhances the ability to reflect on his or her own assumptions and thought processes;

- students develop social and team skills through the give-and-take of consensusbuilding;

- students profit from belonging to a small and supportive academic community; and

- students experience diversity which is essential in a multicultural democracy (Matthews, Cooper, Davidson, \& Hawkes, 1995).

\section{Environments}

\subsection{Learning environments}

Learning takes place everywhere and at all times. This learning is often not intentional in nature and is simply the result of having had experiences. This means that life itself is the primary environment for learning, albeit not necessarily for intentional learning. Society has deemed it desirable and necessary to create artificial environments for intentional learning both to increase its efficiency and to standardise or certify its nature. The school is an example of such an environment.

Morrison and Collins (1996, p. 109), referring to the multiplicity of ways in which it is possible to know about things in the modern world, advance an argument for "epistemic fluency", which they describe as "the ability to identify and use different ways of knowing, to understand their different forms of expression and evaluation, and to take the perspective of others who are operating within a different epistemic framework". Knowing is no longer tied to what is stored in one's head, but is tied to context, distributed across the individual, situational affordances and other people (Hewitt, Scardamalia, \& Webb, 1997).

Making use of what has already been previously stated, one can characterise a competency based learning environment as being the intersection of learning tasks, learning groups and learning contexts. The learning tasks provide the intention for learning and are the gateway to the knowledge and skills needed for the completion of those tasks. The learning groups provide the learner with the opportunity to gain the higher-order skills and attitudes necessary for success in a profession and in society in general. The learning contexts provide the situations, which make learning meaningful and viable.

\subsection{Learning tasks}

It is clear that the traditional school is not - at this moment - the place to acquire this epistemic fluency. Ohlsson (1996) enumerates seven epistemic tasks (describing, explaining, predicting, arguing, critiquing, explicating, defining) which 
give a basis for what Goodyear (1998) calls a core consensual purpose for higher education - the fostering of epistemic fluency. These tasks may be viewed as characteristics of a new type of learning environment.

\subsection{Groups}

Beyond these tasks, a learning environment for collaborative learning has to provide a working basis which take into account, often organisational, factors such as time, space, size and make-up of groups and tools available.

\subsection{Contexts}

Beyond this, a learning environment needs to provide a context for collaboration. This context needs to provide a common ground for collaboration in which participants share mutual knowledge, beliefs and assumptions.

\subsection{Electronic learning environments}

When deciding to make the step from a learning environment to an electronic learning environment it is useful to ask "the media" what it modifies, what it renders obsolete, what it retrieves that was previously obsolesced, and how does it evolve (McLuhan \& McLuhan, 1988).

Electronic learning environments provide possibilities for taking the different aspects of learning environments discussed in the previous section into account. It goes far beyond the scope of this contribution to enumerate all of the different aspects of all of the different tools and possibilities that information and communication technologies provide. Suffice it to say that the market is flooded with hardware and software, but that their optimal integration is more often than not a problem and not a solution.

\subsection{Integrated electronic leaning environments}

Integrated (powerful) Electronic Learning Environments are learning environments that make use of modern synchronous and asynchronous information and communication technologies to connect the different subsystems of education to each other. Education, whether it is the most traditional type that we know of or the most advanced and information technological that exists, always must consist of minimally five discrete, but interacting systems or environments. For collaborative work, these environments are: a task environment (a task in the relevant content area), a study environment (the chosen didactic method, i.e. case-based, problem oriented, project oriented), a group or project environment with communication possibilities (a social interaction system), an administrative environment (a system for planning, recording study progress, dossier storage, and so forth) and a technical environment (technical system of which the individual student is a part). The assumption for the design process is that these five systems should be functionally compatible and interrelated. 
Fig. 1 shows an integrated environment from a systems perspective.

The technologies used include stand-alone and distributed software and tools, CDROM, multimedia and Web-based environments and typically allow learners in a distributed environment to communicate with each other (and with tutors and mentors) and access tools to optimise their learning. They ideally make use of rich learning tasks, just-in-time information presentation, student specific support structures and authentic assessment procedures. Finally, they provide tools that stimulate learner evaluation and reflection. An example of such an environment is the Knowledge Integration Environment (Bell, Davis, \& Linn, 1995) at the University of California at Berkeley. This environment combines network resources and software with sound pedagogical principles to improve science learning. Students work collaboratively to answer scientific questions using evidence from the WWW and tools such as an electronic notebook and on-line discussion tools to make collaborative decisions.

The Open University of the Netherlands has designed and developed just such an integrated electronic learning environment called ELON-Systems ${ }^{\circledR}$ — Education and Learning ON-line Systems (Koper, Rikers, \& Valcke, 1998). Central to this environment is the stimulation of study and learning activities, which are selected on the basis of the competencies that the student wants to acquire. Based upon an intake procedure which makes use of the personal profile of the student, a competency catalogue and a systematic competency map, each student can be offered a personal educational arrangement composed of a set of study tasks. These tasks "guide" the learning process and refer the student to both the necessary information (e.g., texts, multimedia, URLs) and the available guidance and support facilities. Some tasks can be done individually, but most require collaborative work for which

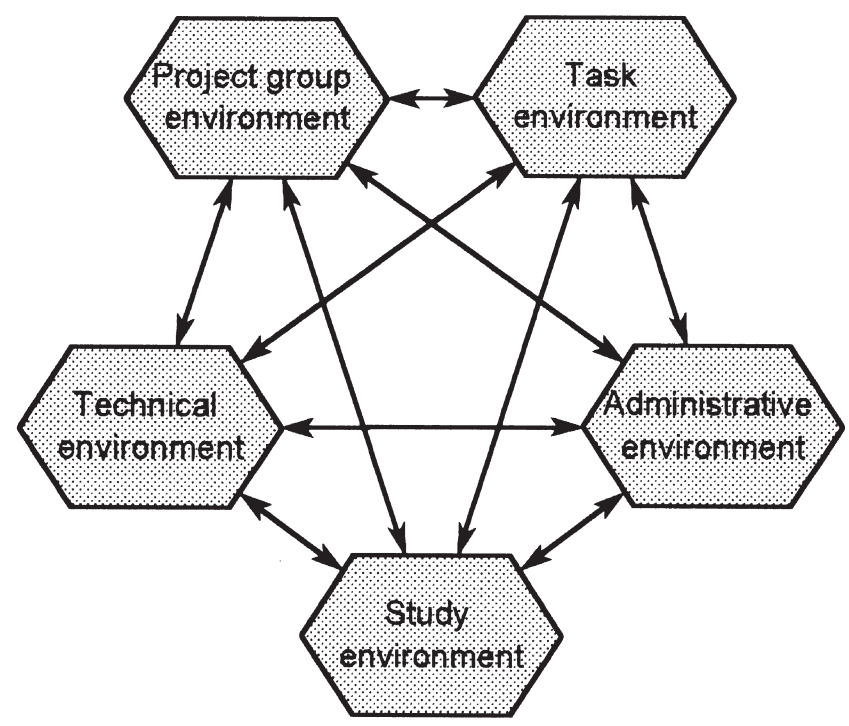

Fig. 1. The environment from a systems perspective. 
the environment also provides the facilities. Finally, assessment of both progress and competency acquisition are part and parcel of the agreed upon educational arrangement and are integral to the environment.

The components of this integrated electronic learning environment are:

1. The availability of a competency catalogue and map

2. The building and making available of educational arrangements for students and groups of students and educational units

3. The availability of study tasks and study assignments

4. The use of flexible, just-in-time learning materials

5. The availability of support facilities for the different actors

6. The definition of actors and their roles in the study process

7. Formative and summative (certification) assessment via alternative and authentic assessment forms

\section{Conclusion}

It is clear University education must change. It must change from its historical roots as an institution dedicated to producing, imparting and preserving knowledge into a new type of institution dedicated to encouraging, allowing and facilitating its members to become socially and academically competent professionals (either in the business world or in academia) within integrated communities of learners and scholars. Integrated powerful electronic learning environments "afford the design of whole new learning environments with more self-guided exploration, more collaborative work across distances [and] more intellectual interactivity" (Salomon, 1999).

\section{References}

Assiter, A. (1995). Transferable skills in higher education. London: Kogan Page.

Barnett, R. (1997a). Towards a higher education for a new century. University of London: Institute of Education.

Barnett, R. (1997b). Higher education: a critical business. Buckingham: Open University Press.

Bell, P., Davis, E. A., \& Linn, M. C. (1995). The knowledge integration environment: Theory and design. In J. L. Schnase, \& E. L. Cunnius, Proceedings of CSCL'95: The first international conference on computer support for collaborative learning (pp. 14-21). Mahwah, NJ: LEA.

Boyatzis, R. E. (1982). The competent manager. A model for effective performance. New York: Wiley.

Brown, J. S., Collins, A., \& Duguid, P. (1989). Situated cognition and the culture of learning. Educational Researcher, 18 (1), 32-42.

Collins, A. (1988). Cognitive apprenticeship and instructional technology. Technical Report No. 6899. Cambridge, MA: BBN Labs Inc.

De Snoeck, J. (1997). Zoeken naar de receptuur: competentiemanagement [Searching for a recipe: Competency manager]. In N. V. Bekaert, (pp. 40-45). Gids voor Personeelsmanagement, 76.

Dillenbourg, P., Baker, M., Blaye, A., \& O’Malley, C. (1995). The evolution of research on collaborative 
learning. In P. Reimann, \& H. Spada, Learning in humans and machines. Towards an interdisciplinary learning science (pp. 189-211). London: Pergamon.

Gagné, R. M. (1985). The conditions of learning. (4th ed). New York: Holt, Rinehart and Winston.

Goodyear, P. (1998). New technology in higher education: understanding the innovation process. Keynote presented at the International Conference on Integrating information and communication Technology in Higher Education (BITE), Maastricht, The Netherlands.

Harvey, L., \& Knight, P. (1996). Transforming higher education. Buckingham: Open University Press.

Harvey, L., \& Mason, S. (1996). A quality graduate. In J. Tait, \& P. Knight, The management of independent learning (pp. 13-28). London: Kogan Page.

Hewitt, J., Scardamalia, M., \& Webb, J. (1997). Situative design issues for interactive learning environments: The problem of group coherence. Paper presented at the Annual Meeting of the American Educational Association, Chicago.

Keen, K. (1992). Competence: What is it and how can it be developed? In J. Lowyck, P. de Potter, \& J. Elen, Instructional design: Implementation issues (pp. 111-122). Brussels, Belgium: IBM International Education Center.

Kirschner, P. A., van Vilsteren, P., Hummel, H., \& Wigman, M. (1997). A study environment for acquiring academic and professional competence. Studies of Higher Education, 22 (2), 151-171.

Koper, R., Rikers, J., \& Valcke, M. (1998, July). Definitiestudie ELO [ELO definition study]. Open Universiteit Nederland: OTEC.

Laurillard, D. (1993). Rethinking university teaching: a framework for the effective use of educational technology. London: Routledge.

Matthews, R. S., Cooper, J. L., Davidson, N., \& Hawkes, P. (1995). Building bridges between cooperative and collaborative learning. Change, 27, 34-40.

McLuhan, M., \& McLuhan, E. (1988). Laws of Media. Toronto, Ontario, Canada: University of Toronto Press.

Mirande, M., Riemersma, J., \& Veen, W. (1997). De digitale leeromgeving [The digital learning environment]. Hoger Onderwijs Reeks. Groningen: Wolters Noordhoff.

Morrison, D., \& Collins, A. (1996). Epistemic fluency and constructivist learning environments. In B. Wilson, Constructivist learning environments (pp. 107-119). Englewood Cliffs: Educational Technology Press.

Ohlsson, S. (1996). Learning to do and learning to understand. In P. Reimann, \& H. Spada, Learning in humans and machines (pp. 37-62). Oxford: Pergamon.

Panitz, T. (1996). Collaborative versus cooperative learning [On-line]. Available WWW: http://ericae.net/k12assess/colcoo.htm

Salomon, G. (1999). Higher education facing the challenges of the information age. Invited address read at the Catholic University of Leuven, Belgium by the bestowing of an honorary degree.

Spiro, R. J., Coulson, R. L., Feltovich, P. J., \& Anderson, D. K. (1988). Cognitive flexibility theory: Advanced knowledge acquisition in ill-structured domains. Tech. Rep. No. 441. Champaign, IL: University of Illinois, Center for the study of reading.

van Merriënboer, J. J. G. (1999). Cognition and multimedia design for complex learning. (Inaugural address available from the Educational Technology Expertise Center of the Open University of the Netherlands, PO Box 2960, 6401 DL, Heerlen, The Netherlands)

von Glasersfeld, E. (1988). Cognition, construction of knowledge and teaching. (Eric Document Reproduction Service No. ED 294 754). 